\title{
Thoughts on the Inheritance of Shaanxi Folk Dance in Universities
}

\author{
Bo Tan \\ Xi'an Physical Education University, Xi'an 710068, China.
}

How to cite this paper: Bo Tan. (2021). Thoughts on the Inheritance of Shaanxi Folk Dance in Universities. The Educational Review, USA, 5(7), 208-212. DOI: 10.26855/er.2021.07.004

Received: June 18, 2021

Accepted: July 12, 2021

Published: July 26, 2021

Corresponding author: Bo Tan, Xi'an Physical Education University, Xi'an 710068, China.

Email: tanyutaibo@163.com

\begin{abstract}
Global integration and cultural diversification have brought various challenges to China, and Chinese folk dances are facing severe challenges. As a part of folk culture, Shaanxi folk dance has also suffered major traumas, and the inheritance of folk dance has been in a difficult situation. Whether the inheritance problem can be properly resolved has become a shackle that affects the development of folk dance. The participation of universities in the protection and inheritance of folk dance is a mission entrusted by the development of the times and society. It is of great significance for inheriting excellent traditional culture, carrying forward the national spirit, and enhancing cultural self-confidence. In this context, the author chose this topic to explore the sustainable development strategy of folk dance culture in colleges and universities from the perspective of education and inheritance. I hope to make efforts and contributions to protect and inherit the excellent folk dance culture of Shaanxi.
\end{abstract}

\section{Keywords}

Shaanxi, Folk Dance, Inheritance, College Education

\section{Introduction}

Folk dance, as an important part of intangible culture, carries the long cultural tradition of mankind, condenses the historical and cultural value of the nation, and is an important manifestation of ethnic regional activities. As a major cultural province, Shaanxi has a long history and cultural resources, rich folk cultural heritage, and various forms of folk dances add to the splendid culture of Shaanxi. However, in recent years, the advent of economic globalization has brought various challenges to China, which have greatly impacted people's aesthetic appeal, way of thinking, and value orientation (Li, C. 2017). Folk dances in Shaanxi have also suffered major traumas, and folk dances are gradually disappearing. Therefore, whether the inheritance problem can be properly resolved has become a shackle that affects the development of folk dance. This article mainly explores the sustainable development of folk dance culture in colleges and universities from the perspective of education and inheritance.

\section{Overview of Shaanxi Folk Dance}

\subsection{Introduction to Shaanxi Folk Dance}

Folk dance originated from primitive dance, and has been gradually accumulated and developed by the working people after a long history. It is enduring among the people. It reflects the spiritual and material lives of the working people, and expresses people's thoughts, feelings and aesthetic ideals. The folk dances created by Shaanxi, such as northern Shaanxi Yangko, Ansai waist drum, old Yangko, Di Yangko, Changzi, and chest drum, have made Shaanxi a "sea of singing and dancing" and "a treasure house of art". These local traditional cultures have invigorated the cultural 
life of the masses, demonstrated the spirit of Shaanxi, and passed on from generation to generation among the people.

Since the founding of the People's Republic of China, the province has successively discovered more than 260 types of folk dances, among which more than 40 are rare forms. According to the analysis of the purpose, function, artistic form and characteristics of Shaanxi folk dance activities, it can basically be summarized into three categories, namely, social fire, folk sacrifices, and folk small dramas. There are nearly a hundred forms of folk dances in northern Shaanxi. The more common folk dances include Yangge, water boat, lion dance, overlord whip, waist drum, dragon dance, kicking field, etc. Among them, Yangge and waist drum have become the business cards of northern Shaanxi folk dance (“Chinese Dance History” Editorial Committee, 2009). The Guanzhong area takes social fire as the main form of expression. Common dance programs include: stilts, cores, lions, dragon lanterns, bamboo horses, local stories, and social fires on the ground. The Huaguzi, Dibengzi, Lotus-picking Boat, Xiaochangzi, Four Boats, Drums and Bench Dragon in Southern Shaanxi have formed a lyrical, soft, cheerful and lively style due to the influence of Chu culture and Bashu culture. These dance arts have distinctive characteristics. They are not only a unique presentation of the regional culture and folk customs of Shaanxi, but also a vivid reflection of the beliefs and concepts bred by this land, and have important protection and research value.

\subsection{The value and significance of the inheritance of Shaanxi folk dance}

Shaanxi is the birthplace of Chinese civilization. Here you can see the colorful classical culture, thousands of years of history and cultural accumulation, which demonstrates the profoundness of the culture, which has also had a profound influence on the folk dance art rooted here (Zhang T., 2015). Shaanxi folk dances have a large number, various themes, rich forms and diverse styles. Therefore, it is of great significance to study the inheritance of Shaanxi folk dances. First, it is an important subject of cultural construction in our province (Si, Bai, \& Wang, 2021). Culture is a reflection of national characteristics. Folk dance has always been regarded as the "soul of national culture". Folk dances in various forms are an important part of traditional cultural heritage, which most directly reflect the character, lifestyle, and material culture of the people in the region. The study of the inheritance of folk dance enables the continuation and development of national culture. The second is the need to inherit the national spirit and enhance national cohesion. The national spirit is passed down after a long period of development, and it is the driving force for the development and growth of a nation. The inheritance of folk dance constitutes the spiritual power for a nation to prosper and develop. The third is the need to maintain cultural diversity in Shaanxi. Cultural diversity is an effective means to promote the prosperity of socialist culture and promote the healthy development of human society, and it has an irreplaceable effect on the development of human society. Fourth, it has the special significance of intangible cultural heritage protection. In the context of today's global economic integration, many folk dances in Shaanxi are on the verge of extinction and are facing serious challenges. The protection of intangible cultural heritage and the protection of Shaanxi's original ecological folk dance have become the top priority at the moment (Zhu X.Y., 2021).

\subsection{The status quo of the inheritance of Shaanxi folk dances}

Shaanxi folk art has a profound cultural heritage and rich intangible cultural relics. However, from a social perspective, with the advent of the industrialization and information age, people's artistic and cultural consumption needs have become increasingly diversified, coupled with the impact of popular culture and commercial culture on the original ecological culture in the market economy environment, making folk culture and art living space is getting narrower. Traditional Shaanxi folk art forms have problems such as insufficient innovation, backward business models, insufficient communication, and outdated content and forms. They are no longer able to adapt to the fast-developing society and the increasing needs of consumers.

For the rescue of Shaanxi folk dances, the dancers have done a lot of protection work, including collecting physical materials from the folks, analyzing typical cases, organizing collection activities on a regular basis, etc., and sorting out the materials on this basis, and then giving special lectures and papers. Write books, conduct subject research, etc., the masses will also organize these traditional dance art on important festivals, which can make more people understand and make the traditional art spread. At the same time, the national government has also launched a rescue and protection project, and the "Intangible Cultural Heritage Protection Law of the People’s Republic of China" was officially promulgated and implemented, providing legal guarantees for the protection of intangible cultural heritage. Government departments have also gradually launched the census of intangible cultural heritage, heritage collection, personnel training, records, and the establishment of a network platform. And set up various intangible cultural heritage protection centers, inheritance bases and inheritor systems, and hold various intangible cultural heritage project exhibitions and activities to strengthen the inheritance and protection of Shaanxi folk art. At present, folk dances such as Northern Shaanxi Yangko, Northern Shaanxi Waist Drum, Qianzhou Jiaolong Drum, and Chenggu County Water Beast Dance have been selected 
as "National Intangible Cultural Heritage List”.

Nevertheless, the inheritance of traditional culture and art in Shaanxi is still not optimistic. The inheritance of Shaanxi folk dance still has the following problems: 1 . The inheritors are generally older and have a lower average education level (Li, C., 2017); 2. There is a gap in the cultivation of inheritors. 3; The inheritance organization lacks standardized management, and the current grassroots organization management is insufficient; 4. Basic-level associations lack professional cadres and talents; 5 . Single inheritance method, simple inheritance method, insufficient market awareness and large-scale production. For these reasons, the status quo of Shaanxi folk dances is facing loss and extinction. The status quo of folk dances such as "Water Beast Dance" is extremely endangered and its development is in an embarrassing situation.

\section{The important role of colleges and universities in the inheritance of Shaanxi folk dance}

The inheritance method of Shaanxi folk dance has continued the ancient inheritance method, and the inheritance method is relatively simple. Dance education is obviously an important way to popularize, promote and inherit the folk dance culture. As an important place for cultural dissemination, cultural exchange, and education, colleges and universities seem to have forgotten the important role they played in the protection and spread of dance art. At present, Shaanxi dance schools still follow the almost identical curriculum system of most professional schools. The teaching content of folk dance is still Han, Tibetan, Uyghur, Mongolian, Korean and other ethnic groups (Zhao L. M., 2009). Northeast Yangko and Jiaozhou Yangko have become Yangko teaching. Shaanxi is a big province of Yangko, but Yangko in northern Shaanxi has not been systematically organized and promoted, and a stable teaching system has not been formed.

Institutions of higher learning have a large space for the inheritance of Shaanxi folk dances. The author believes that colleges and universities have the conditions for theoretical research and teaching practice of Shaanxi folk dance. Offering relevant courses of Shaanxi folk dance and holding relevant practical activities in colleges and universities can not only ensure the effective inheritance of Shaanxi folk dance, spread and carry forward the local culture. At the same time, education can be combined with local cultural forms, constructing teaching content with local characteristics, and a dance education brand rich in local culture, so as to achieve a win-win situation for inheritance and education. College education provides a platform and space for the research of Shaanxi folk dance, and cultivates reserve talents for the protection and inheritance of traditional national culture and art. Due to the stability and sustainability of college education, a strong guarantee is given to the protection and inheritance of folk dances. At the same time, the inheritance of Shaanxi folk dance in colleges can effectively break through the limitations of the dance teaching model of professional colleges, so that students can fully understand the national culture in the process of learning folk art, increase national self-confidence, and cultivate a sense of national belonging.

\section{Measures to be taken by colleges and universities in the inheritance of Shaanxi folk dance}

The inheritance and development of Shaanxi folk dance is a long-term and arduous systematic project. The following will analyze and discuss what measures colleges and universities should take in the inheritance of Shaanxi folk dance.

\subsection{Establish students' national cultural concepts}

The 5,000-year history of Chinese civilization has created and preserved a colorful cultural heritage with unique ethnic and regional characteristics for us. As descendants of Yan and Huang, when folk culture faces various challenges, everyone should have this sense of mission and responsibility (Zeng Z., 2003). As a professional in the dance field, you should actively and bravely contribute your own strength. Nowadays, the challenges brought by the globalization of culture have become more and more severe. It is not difficult to find that those classic works and outstanding performances that are active on the international stage bear a deep national mark. Therefore, it is very important to cultivate students' sense of identity with their own national culture, which is also one of the core values to be realized by local colleges and universities. Therefore, in the process of dance education in colleges and universities, the first thing we have to do is to establish students' strong national cultural concepts, so that students will have a heavy sense of identity and responsibility when facing the broad and profound Chinese culture. In order to clarify one's own responsibilities, take the inheritance of folk dance as a mission to complete.

\subsection{Construct a reasonable Shaanxi folk dance curriculum system}

The curriculum system is the main carrier for the training of advanced talents. Local colleges and universities can plan and regularly set up various courses according to the local artistic characteristics to highlight the regional, national 
and unique characteristics of local dance teaching (Shan, Xu, \& Wang, 2021). Folk dances such as Northern Shaanxi Yangko, Ansai Waist Drum, and Shaanxi Folk Drum Dance are the best choice for local dance courses because of their abundant materials, long spreading time, and strong style characteristics. They are well-known throughout the country and the world. At the same time, scientifically arrange the ratio of theoretical courses and professional courses to strengthen the theoretical study of folk dance, and correspondingly increase the proportion and categories of dance cultural theory courses in the region, such as Shaanxi folk dance history, folk customs and folk music courses, so that students Study the theory of folk dance in a comprehensive, systematic and in-depth way to fully understand the cultural and ideological connotation of Shaanxi folk dance.

\subsection{Improve the construction of Shaanxi folk dance teaching materials}

The construction of teaching materials is the material condition for the dissemination of academics in colleges and universities, and the main basis for teachers to impart knowledge. In order to inherit and inherit Shaanxi folk dances in colleges and universities, it is necessary to improve the supporting folk dance teaching materials to provide stable and clear educational resources for the inheritance of Shaanxi folk dances. At present, Shaanxi professional colleges have not published a Shaanxi folk dance teaching material. Dance educators should start from the characteristics of local ethnic culture, use a macro cultural perspective, seek relevant cultural symbols of specific folk dances, and explore local teaching materials. Through in-depth field investigations, extensive and large collections of Shaanxi folk dance materials, research on local folk dance culture, analysis of typical and representative movement patterns, mastery of movement rhythm and style characteristics, and methods of refining, decomposing and reconstructing each creation and compilation of various forms of folk dance, and the publication of supporting theoretical teaching materials. Strive to explore an educational brand road with strong local characteristics in a hundred flowers blooming folk dance teaching materials.

\subsection{Exploring personalized teaching methods for inheriting folk dances}

In the modern educational development pattern, most of the classroom teaching of dance is oral and personal teaching, which has formed a fixed academic model. However, in order to maintain the original and simple style of the original ecological folk dance and maintain the vitality of the folk dance, college education. It is also necessary to develop a personalized teaching method.

Adopt a combination of insisting on going out and inviting in, let folk artists come into the classroom to tell their artistic experience, dance experience, teach the original ecological dance movements, skills, etc., so that students can directly experience the mind dynamics of folk artists performing. You can also step out of the school, go deep into folk customs, and directly feel the charm of folk dance in the original folk culture environment. In addition, use modern teaching methods and multimedia teaching methods to expand teaching effects and achieve the purpose of cultural heritage.

\subsection{Strengthen the creation and dissemination of Shaanxi folk dances}

The inheritance and protection of folk dances need to be accepted and recognized by the public. While protecting the original ecological dance, it creates excellent works of new modern folk dance that meet the needs of today's aesthetic and social culture. This requires dancers to process and create folk dances after they have learned them, and complete the transformation of folk dances from the original ecology to the classroom and then to the theater, that is, to grasp the essence and soul of the original ecology dance and have a novel form that is easy for the public to accept (Chen \& Zhu, 2021). To maximize the inheritance of the essence of national dance. At present, there are very few repertoires created based on the original ecological folk dance in our province. The dances "Drum Red" and "Chasing the Drum" based on the theme of folk dance in our province are the professional colleges and universities in our province in protecting and inheriting the folk dances. Shaanxi folk dance is rich in resources and diverse, and there is still a huge space for exploration in terms of creation.

\section{Concluding Remarks}

Today, when Shaanxi folk dance is facing such a big challenge, what kind of measures and attitudes colleges and universities adopt in folk dance have a great influence on its protection and inheritance. This requires colleges and universities to pay full attention to the development and inheritance of folk dance in the dance teaching process, firmly establish their own sense of mission, and incorporate the cultural heritage of ethnic dance with great aesthetic habits and charm into the entire ethnic dance education framework system in. Although today in the 21st century, ethnic dance 
faces great challenges, it is also destined to be a period of great development. Dance educators in institutions of higher learning should seize this opportunity to organically integrate our modern educational concepts and methods with the development and inheritance of folk dance culture, and make due contributions to the protection and inheritance of folk dance resources.

\section{References}

“Chinese Dance History” Editorial Committee. (2009). Chinese Dance History Shaanxi Volume. Shanghai: Xuelin Publishing House.

Chen, L. and Zhu, Q. Z. (2021). The Innovation of Chinese Folk Dance Culture from the Perspective of Cultural Inheritance. Modern and Ancient Cultural Creation, (16), 87-88.

Li, C. (2017). Overview of Shaanxi Dance Development. Symphony (Journal of Xi'an Conservatory of Music), 36(02), $110-113$.

Liu, C. (2021). Research on the inheritance law and development trend of ethnic folk dance culture. Grand View of Art, (15), 80-81.

Shan, N., Xu, S. H., and Wang, D. (2021). Research on effective strategies for the inheritance of folk dance culture in colleges and universities from the perspective of intangible cultural heritage. Artwork Jian, (06), 124-125.

Si, X. H., Bai, K. L., and Wang, C. S. (2021). “Shaanxi Cultural Development Report”. Social Science Literature Press.

Zeng, Z. (2003). How to pass on folk dance art in college education. Big Stage, (04), 170-171.

Zhang, T. (2015). Contemporary Inheritance and Protection of Shaanxi Folk Dance "Pipe Dragon”. Shaanxi Education (Higher Education), (02), 24-26.

Zhao, L. M. (2009). Thoughts on the education of ethnic folk dance triggered by intangible cultural heritage. Yihai Shibei, (04), 12-13.

Zhu, X. Y. (2021). Research on the Inheritance and Teaching Path of "Intangible Cultural Heritage” Folk Dance in Local Universities. Media Forum, 4(02), 109-110. 